\title{
Substrate Integrated Waveguide (SIW) Coupler on Green Material Substrate for Internet of Things (IoT) Applications
}

\author{
Nurehansafwanah Khalid $^{1 *}$, Siti Zuraidah Ibrahim ${ }^{1}$, and Fwen Hoon Wee ${ }^{1}$ \\ ${ }^{1}$ Advanced Communication Engineering Centre (ACE) School of Computer and Communication Engineering, Universiti Malaysia \\ Perlis, Arau, Perlis, Malaysia
}

\begin{abstract}
This paper shows designed coupler on paper-substrate with Substrate Integrated Waveguide (SIW) techniques. Types of paper-substrate that used are photographic paper. The rectangular coupler is presented with Substrate Integrated Waveguide (SIW) which metallic via on paper-substrate. The structures of the coupler are designed and analysed using Computer Simulation Tools (CST) Studio Suite 2014 Software. This designed coupler operating within frequency of 3.8-5 GHz. The paper-based substrates are permits the implementation of green materials (Eco-friendly) technology. The design of the coupler and its simulated results are reported in this paper.
\end{abstract}

\section{Introduction}

Nowadays, there are huge interest with a new emerged technology known as Substrate Integrated Waveguide (SIW) in communication systems [1]. Substrate Integrated Waveguide (SIW) functions as a bridge technology which combines metallic waveguide and planar circuits. Integrated Waveguide Subject Technology (SIW) is also called as laminate-waveguide where it has the advantage to prevent leakage of electromagnetic waves by using metallic via holes [2,3].

The rectangular waveguide is widely used in communications systems due to increases of Q-factor and increases of power. However, the key challenges of this issues is that they are not eco-friendly and environmentally friendly to be implemented in microwave and communications systems especially for IoT applications and life-quality [2,4,5]. The paper substrate is the ideal choice as it is easily accessible, flexible and requires a simple fabrication process [6]. The implementation of paper-based (organic substrate) in electronic components is carried out without the need for etching and the use of chemical acids as opposed to inorganic substances that are hazardous to humans [7]. Paper substrate is suitable for wireless on body network and biomedical applications [7]. Moreover, the basic microstrip lines are easy to design and implement but the drawback it has a high loss radiation [5-8].

The conventional LTCC and PCB technology has increased the pollution impact due to the process of chemical etching and metallization on both surfaces [9 ],[4]. This substance is significantly unsuitable for the environment because the fabrication process uses acids, heavy metals and non-recyclable substrates $[10,11]$.

\footnotetext{
Corresponding author: nurehansafwanah@yahoo.com
}

Thus, the Substrate Integrated Waveguide (SIW) supports the frequency in Transmission Lines (TL) which provides better frequency performance on low substrate dielectric permittivity.

Then, the geometry of Substrate Integrated Waveguide (SIW) structure is not affected and influenced by the dielectric loss. In fact, energy leakage occurs because of the distance (gap) between metallic via [11][13]-[16]. In addition, the advantages of Substrate Integrated Waveguide (SIW) to the performance of electronic system is that it produces compact, flexible and small-sized designs, reducing radiation loss, enhancing power capability and Q-factor system.

The review of previous works of Substrate Integrated Waveguide (SIW) using paper substrate was studied. For example in [5], a half-mode Substrate Integrated Waveguide (SIW) transmission line implemented on paper substrate was presented, indicating that the simulated and measured results of the insertion loss are $2.8 \mathrm{~dB}$ at $4 \mathrm{GHz}$. In turn in [7], the designed bandpass filter was demonstrated at $5 \mathrm{GHz}$ with a insertion loss of $5 \mathrm{~dB}$.

In this paper, Substrate Integrated Waveguide (SIW) using paper substrate is investigated within operating frequency range of 3.8-5 GHz. There are few types of paper substrates that are commercially available in the market including watercolour paper, raw paper and photographic paper. A watercolour paper substrate is commercially available at a thickness of $0.30 \mathrm{~mm}$, with a tangent loss of 0.045 and the dielectric constant of 2.09. A raw paper substrate is commercially available at a thickness of $0.35 \mathrm{~mm}$, has a tangent loss of 0.037 and dielectric constant of 2.11. The photographic paper substrate is commercially available at a thickness of 0.69 
mm, with a tangent loss of 0.044 and a dielectric constant of 2.35. In this paper, the photographic paper substrate is used in the coupler design because the substrate loss in SIW is dependent on the substrate thickness; the thicker the substrate, the better the insertion loss. The design is accomplished using Computer Simulation Tools (CST) software.

\section{Design Techniques}

\subsection{The configuration of Substrate Integrated Waveguide (SIW) cavity}

The configuration of SIW transmission lines is illustrated in Fig. 1.

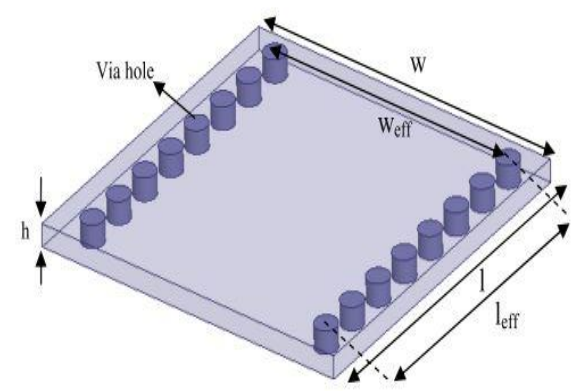

Fig. 1. Basic Structure of Substrate Integrated Waveguide (SIW) [14]

The waveguide substrate are covered with two metal (high conductivity) surfaces on top and bottom to let the propagation of all $\mathrm{TE}_{\mathrm{n} 0}$ modes [15]. The two silver epoxy holes are placed on the side line of the rectangular waveguide that functions to prevent and reduce signal leakage. Both metal posts are set symmetrically in order to control the signal flow. Two extra silver epoxy posts that set in every port act as reflection cancelling elements by varying the sections of Substrate Integrated Waveguide (SIW) [14]. Via hole must be shorted to both planes in order to provide vertical current paths, otherwise the propagation characteristics of SIW will be significantly degraded [14].

\subsection{SIW Coupler's Design}

The configuration and parameter dimensions of SIW coupler are shown in Fig. 2.

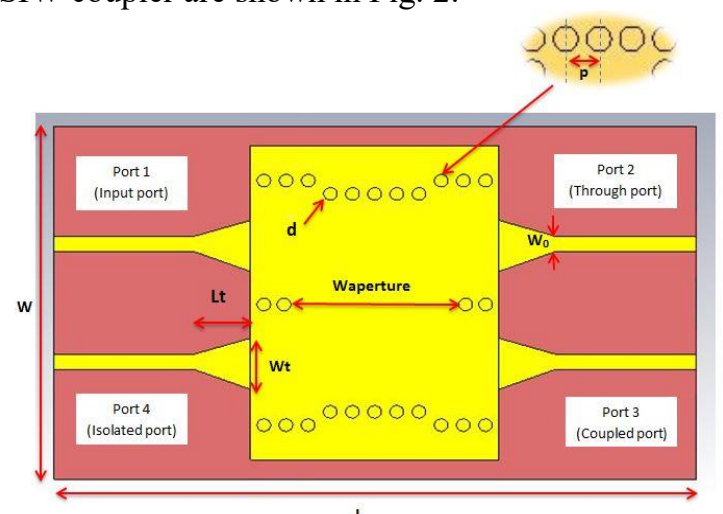

(a)

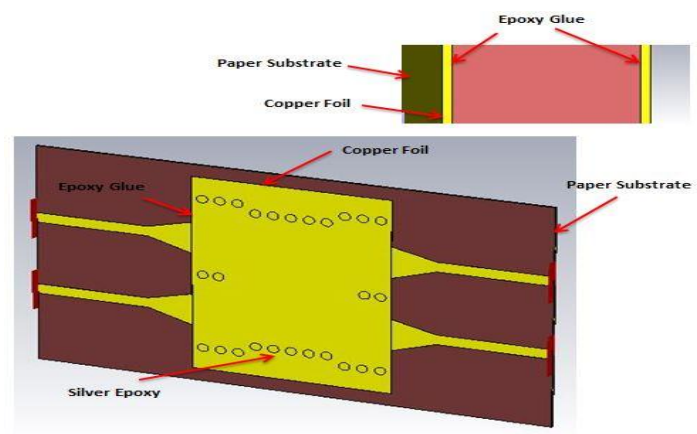

(b)

Fig. 2. Configuration of SIW Coupler (a) Top view (b) Side view

As depicted in Fig. 2, the coupling is obtained by two narrow apertures in the common broadside wall of two adjacent SIWs. To accomplish such coupling ratio, Port 1 is defined as the input port, Port 2 as the through port, Port 3 as the coupled port and Port 4 as the isolated port. The transition between SIWs and microstrip line is realized using microstrip taper to match both electrical and magnetic field distributions between the two medias [14].

In this paper, the proposed coupler is designed on photographic paper substrate materials where the metal (conductive) used is copper as a ground plane and metallic via holes. The relative dielectric constant $\left(\varepsilon_{\mathrm{r}}\right)$ of the photographic paper is 2.35 , thickness $(\mathrm{h})$ is $0.69 \mathrm{~mm}$ and loss tangent $(\tan \delta)$ is 0.044 .

The effective width ( $\left.W_{\text {eff }}\right)$ and effective length $\left(L_{\text {eff }}\right)$ of the Substrate Integrated Waveguide (SIW) cavity shown in Fig. 1 can be determined using expression (1) and (2).

$$
\begin{aligned}
& W_{e f f}=W-\frac{d^{2}}{0.95 s} \\
& L_{e f f}=L-\frac{d^{2}}{0.95 s}
\end{aligned}
$$

Where,

$W$ and $L$ are the width and length of Substrate Integrated Waveguide (SIW) cavity.

Fig. 3 illustrates the two of SIW cavity design main parameters, diameter of metallic via holes $(d)$ and the gap distance between via holes $(s)$.

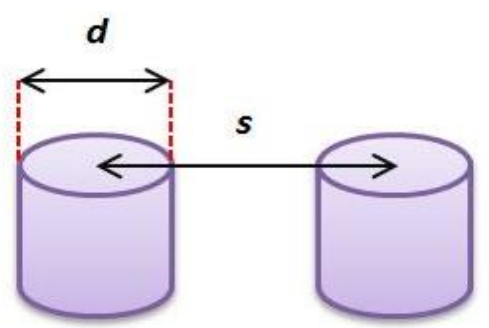

Fig. 3. Via holes SIW cavity's design parameters[11] 
For SIW cavity designs, conditions expressed in (3) and (4) must be followed.

$$
d<\frac{\lambda_{g}}{5}
$$

$$
s \leq 4 d
$$

Where,

$$
\lambda_{g}=\frac{2 \pi}{\sqrt{\frac{\varepsilon_{r}(2 \pi f)^{2}}{c^{2}}-\left(\frac{\pi}{w}\right)^{2}}}
$$

$f$ is the frequency

$c$ is the speed of light

The ratio of $d / p$ is important in order to inhibits leakage loss in SIW, which applicable range is $0.5<d / p$ $<0.8$ [17]. Then, the width of SIW can be defined by expression (6) and (7) [14]:

$$
\begin{aligned}
W_{\text {siw }} & =W_{\text {equi }}+1.08\left(\frac{d^{2}}{s}\right)-0.1\left(\frac{d^{2}}{W_{\text {siw }}}\right) \\
W_{\text {equi }} & =\frac{c}{2 f_{c} \sqrt{\varepsilon_{r}}}
\end{aligned}
$$

The configuration of SIW to microstrip transition is shown in Fig. 4.

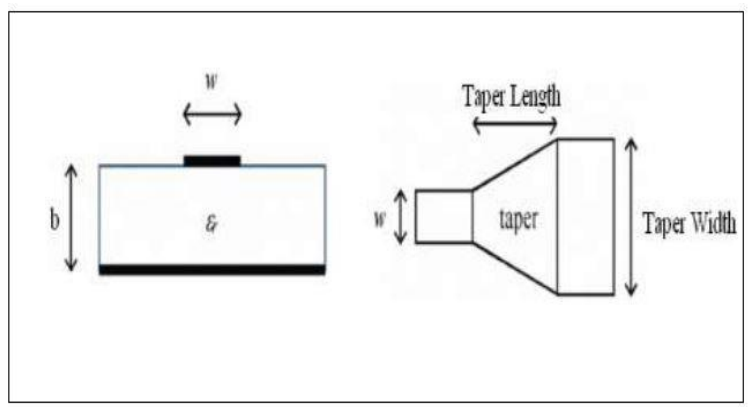

Fig. 4. Basic Geometry of microstrip line and tapered microstrip

The transition between SIW and microstrip basically comprises of tapered microstrip line interconnected with microstrip-waveguide with different width [4]. A tapered microstrip line is important to match the SIW with $50 \Omega$ transmission lines impedance. By following the guidelines given in [18][19], the initial value of tapered width $\left(W_{t}\right)$ and tapered length $(L t)$ shown in Fig. 4 are determined [9][19] using expression (8) to (11).

$$
\frac{W_{t}}{A_{g}} \approx 0.4
$$

$$
\left(\frac{\lambda_{g}}{2}\right)<L_{t}<\lambda_{g}
$$

Where,

$$
\begin{gathered}
\lambda_{g}=\lambda_{c} / \sqrt{\varepsilon_{r}} \\
L_{t}=\frac{n \lambda_{g}}{2}, n=1,2,3,4 \ldots
\end{gathered}
$$

Table 1 shows the optimized dimensions of the SIW coupler.

Table 1. Dimensions of Coupler

\begin{tabular}{|c|c|c|}
\hline Parameters & Descriptions & Dimensions $(\mathrm{mm})$ \\
\hline $\mathrm{L}$ & The length of substrate & 150.00 \\
\hline $\mathrm{W}$ & The width of substrate & 40.00 \\
\hline $\mathrm{d}$ & Diameter of circular via & 3.175 \\
\hline $\mathrm{p}$ & Pitch of circular via & 5.175 \\
\hline $\mathrm{Wt}$ & $\begin{array}{c}\text { Width of microstrip } \\
\text { taper }\end{array}$ & 13 \\
\hline $\mathrm{Lt}$ & $\begin{array}{c}\text { Length of microstrip } \\
\text { taper }\end{array}$ & 13.6 \\
\hline $\mathrm{W}_{\text {aperture }}$ & Width of aperture & 42.39 \\
\hline $\mathrm{W}_{\text {siw }}$ & Width of siw & 27.52 \\
\hline $\mathrm{W}_{\mathrm{o}}$ & Width of microstrip line \\
\hline
\end{tabular}

\section{Results}

The final overall dimensions of the SIW coupler are 150 $\mathrm{mm} \times 40 \mathrm{~mm}$. Fig. 5 shows the simulated results of the proposed SIW coupler. The reflection coefficient, S11 and isolation, $\mathrm{S} 41$ are better than $10 \mathrm{~dB}$ for the frequency range of $4-4.8 \mathrm{GHz}$. The flat coupling of $3 \mathrm{~dB} \pm 1.5 \mathrm{~dB}$ can be observed within frequency range of $4.06-4.8$ GHz. Excellent $90^{\circ} \pm 3^{\circ}$ phase difference between $\mathrm{S}_{21}$ and $\mathrm{S}_{31}$ is observed in Fig. 5(b) with the same frequency range. Considering all the $\mathrm{S}$-parameters performance, the proposed SIW coupler using photographic paper shows acceptable performances and suitable for IoT applications.

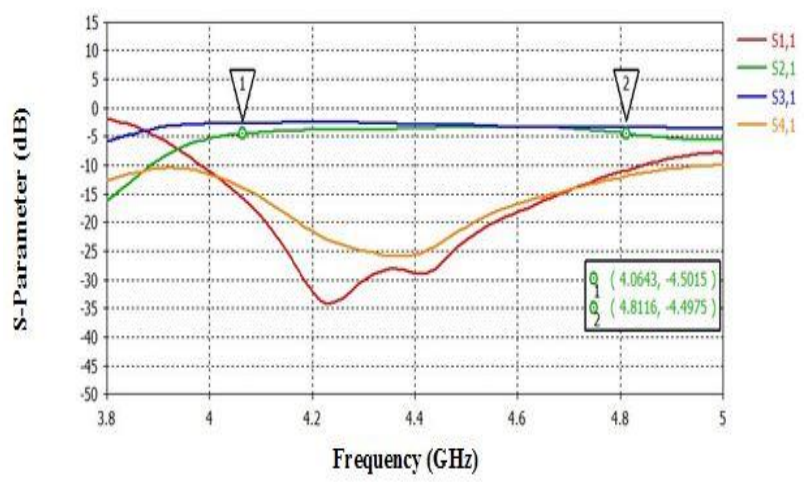

(a) 


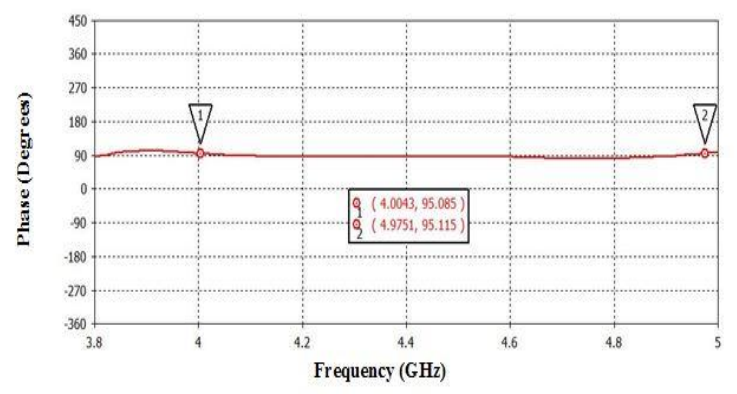

(b)

Fig. 5. Simulated S-parameters of SIW Coupler (a) magnitude in $\mathrm{dB}$ (b) Phase difference between output port

\section{Conclusions}

The design of SIW coupler using photographic paper as a substrate has been presented. The SIW coupler design has been accomplished using electromagnetic software tool, CST Microwave Studio. The simulated results of the coupler show acceptable performances for IoT applications such as for wireless on body network and biomedical applications. The paper-based substrates are permits the implementation of green materials (Ecofriendly) technology.

\section{Acknowledgement}

The author would like to thank the Ministry of Higher Education of Malaysia (MOHE) for the financial support for this research work in terms of FRGS grant of 900300555 .

\section{References}

1. N. Keltouma, F. Mohammed, A. Saghir, "Design and characterization of tapered transition and inductive window filter based on Substrate Integrated Waveguide technology ( SIW )," vol. 8, no. 6, pp. 135-138, (2011).

2. M. Bozzi, "Substrate integrated waveguide (SIW): An emerging technology for wireless systems," 2012 Asia Pacific Microw. Conf. Proc., pp. 788-790, (2012).

3. S. Agneessens, M. Bozzi, R. Moro, H. Rogier, "Wearable textile antenna in substrate integrated waveguide technology," Electron. Lett., vol. 48, no. 16, pp. 985-987, (2012).

4. S. Moscato, R. Moro, M. Pasian, M. Bozzi, L. Perregrini, "Innovative manufacturing approach for paper-based substrate integrated waveguide components and antennas," vol. 10, pp. 256-263, (2016).

5. S. Moscato, N. Delmonte, L. Silvestri, M. Pasian, M. Bozzi, L. Perregrini, "Compact Substrate Integrated Waveguide (SIW) Components on Paper Substrate," pp. 24-27, (2015).
6. R. Moro, S. Agneessens, H. Rogier, A. Dierck, M. Bozzi, "Textile microwave components in substrate integrated waveguide technology," IEEE Trans. Microw. Theory Tech., vol. 63, no. 2, pp. 422-432, (2015).

7. R. Moro, M. Bozzi, "Novel Inkjet-Printed Substrate Integrated Waveguide (SIW) Structures on Low-Cost Materials for Wearable Applications," pp. 72-75, (2012).

8. F. Parment, A. Ghiotto, T. P. Vuong, J. M. Duchamp, K. Wu, "Air-filled substrate integrated waveguide for low-loss and high power-handling millimeter-wave substrate integrated circuits," IEEE Trans. Microw. Theory Tech., vol. 63, no. 4, pp. 1228-1238, (2015).

9. H. Mansor, R. Abdul-rahman, “Optimal Transition in Air-filled Substrate Integrated Waveguide," pp. 172-176, (2015).

10. A. Nasri, H. Zairi, A. Gharsallah, "Design of a Novel Structure SIW 90\&amp;deg; Coupler," Am. J. Appl. Sci., vol. 13, no. 3, pp. 276-280, (2016).

11. A. Kumar, G. Saini, S. Singh, A. Kumar, G. Saini, S. Singh, "Electrical \& Electronic Engineering | Review Article A Review On Future Planar Transmission Line Electrical \& Electronic Engineering | Review Article," Cogent Eng., vol. 48, no. 1, pp. 1-12, (2016).

12. H. A. Ali, R. Bedira, H. Trabelsi, A. Gharsallah, "Cost-effective and Green Manufacturing Substrate Integrated Waveguide ( SIW ) BPF for Wireless Sensor Network Applications," vol. 7, no. 6, pp. 150-154, (2016).

13. S. Kumari, S. Srivastava, "Losses in Waveguide and Substrate Integrated Waveguide (SIW) For Ku Band: A Comparison," vol. 3, no. 1, pp. 5357, (2013).

14. B. H. Ahmad, S. S. Sabri, A. R. Othman, "Design of a Compact X-Band Substrate Integrated Waveguide Directional Coupler," vol. 5, no. 2, pp. 1905-1911, (2013).

15. N. A. Smith, "Substrate Integrated Waveguide Circuits and Systems," no. May, (2010).

16. B. Rahali and M. Feham, "Divider, Circulator and Coupler in [ 10-15 ]."

17. Z. Kordiboroujeni, J. Bornemann, "Designing the width of substrate integrated waveguide structures," IEEE Microw. Wirel. Components Lett., vol. 23, no. 10, pp. 518-520, (2013).

18. B. Rahali, M. Feham, "Substrate Integrated Waveguide Power Divider , Circulator And Coupler In [ 10-15 ] GHz Band," vol. 4, no. 1, pp. 1-11, (2014).

19. D. Deslandes, "Design equations for tapered microstrip-to-Substrate Integrated Waveguide transitions," IEEE MTT-S Int. Microw. Symp. Dig., pp. 704-707, (2010). 